\title{
Temporal changes in the fish community resulting from a summer fishing moratorium in the northern East China Sea
}

\author{
Ya-Zhou Jiang, Jia-Hua Cheng*, Sheng-Fa Li \\ East China Sea Fisheries Research Institute, Chinese Academy of Fisheries Science, 300 Jun Gong Road, \\ Shanghai 200090, PR China
}

\begin{abstract}
The summer fishing moratorium system practiced annually by the Chinese government aims to protect fishery resources and restore the marine ecosystem in the East China Sea. To evaluate the effects of the moratorium on the fish community, temporal changes in the structure and function of the fish community in the northern East China Sea were examined based on data from bottom trawl surveys from 2000 to 2007 . The results revealed that the fish community has undergone a directional change, in terms of relative biomass composition, following the implementation of the moratorium, with increasing trends in Pseudosciaena polyactis and Lophius litulon and decreasing trends in Pampus argenteus and Acropoma japonicum. However, the changes in species composition have not resulted in the expected positive changes in the functioning of the fish community. The fish community in the study area was still moderately or heavily disturbed, based on abundance-biomass comparison analysis. Moreover, no positive trends were observed in the indicators related to the stability and functioning of the fish community (e.g. the biodiversity and the slope and intercept of the size spectrum). Therefore, the summer moratorium system does not clearly fulfill restorative expectations for the fish community. To protect the health of this ecosystem, a comprehensive set of further fishery restrictions must be imposed in the area.
\end{abstract}

KEY WORDS: Fishing moratorium $\cdot$ Fish community $\cdot$ Community dynamics $\cdot$ Diversity $\cdot$ Size spectra

Resale or republication not permitted without written consent of the publisher

\section{INTRODUCTION}

Heavy fishing is a major threat to the structural and functional organization of marine ecosystems (Hall 1999, Hollingworth 2000, Jackson et al. 2001). In the East China Sea (ECS), most of target stocks were under-exploited before the 1980s, and the fish community was in an almost pristine state due to the low fishing pressure (Cheng \& Fan 2001, Xu \& Liu 2007). Since the 1980s, fishing equipment has been improved, and the number of fishing vessels has increased greatly. Hence, the fishing pressure on commercial stocks has increased considerably. Due to the intense fishing pressure, decreases in the abundance of main target species and the commercial extinction of some important species, such as croceine croaker Larimichthys crocea and elongate ilisha Ilisha elongate, have been observed in the ECS during the 1980s to 1990s (e.g. Lin \& Cheng 2004, Ling et al. 2006). Moreover, changes in fish community structure have also been detected (Cheng \& Yu 2004). The community-level changes were especially remarkable in the northern East China Sea (NECS), which is considered one of the most important marine fishing grounds in China. The excessive exploitation of marine fish has led to a great loss in biodiversity and changes in the structure and species composition of the fish community in the area. The dominance of small, fast-growing and non-commercial species in the late 1990s, including glowbelly Acropoma japonicum, benttooth Champsodon snyderi, cardinalfish Apogon lineatus, increased significantly compared to that in the pristine state in the 1960s, whereas 
a decrease in the relative abundance of large-scale, commercial species and in the mean weight of these populations were observed under the impacts of fishing (Cheng et al. 2006, Li et al. 2007).

In order to protect fishery resources effectively, the Chinese government has since 1998 implemented a new seasonal fishing moratorium system (annually from 16 June to 15 September) in the sea areas north of $26^{\circ} \mathrm{N}$. During the annual moratorium, the 2 main types of fishing gear (bottom trawling and stow net fishing) are banned. Fishing efforts declined sharply in summer, following the declaration of the moratorium, and subsequently returned to the original level after the 3 mo moratorium.

Since most fish species in the study area spawn annually in summer (Zhuang et al. 2006), the summer fishing moratorium system was expected to protect the young of importantly commercial species and restore the disturbed marine ecosystem. Previous studies revealed that some target stocks have restored gradually. Catch rates and fish sizes for these stocks have increased to different degrees (Cheng et al. 1999, Yan et al. 2006). But how the status of the fish community has changed since the implementation of the moratorium was not clear. Hence, we used a suite of community metrics to explore changes in the structure of the fish community during the recent decade, which should help us to comprehensively evaluate the effects of the moratorium.

However, we could not simply evaluate the effects of the moratorium on the fish community by comparing the 2 discrete time series separated by the implementation of fishing moratorium system, because there was no comprehensive information on the status of the fish community structure prior to the full implementation of the fishing moratorium in the NECS. Hence, we must look for consistent changes over time that might indicate the effects of the summer fishing moratorium system on the fish community. Changes in the fish community in a presumably positive direction, which would be reflected through temporal changes in community metrics, were expected following the moratorium. If consistent changes occurred and there was evidence that the changes were caused by decreased fishing pressure following the moratorium, we could conclude that the moratorium had played a positive role in the restoration process of the fish community in the study area.

Several community metrics have been proposed to reflect the changes in the fish community in relation to fishing (Rice 2000, Rochet \& Trenkel 2003). Most are sensitive to specific aspects of structural or functional change in a community, and each has particular advantages and disadvantages (Magurran 1988, Greenstreet \& Hall 1996, Rice 2000). Thus, we examined mul- tiple indicators to capture the structural and/or functional changes in the study community. We used species diversity indices to examine the variation in species richness and evenness, abundance-biomass comparison $(\mathrm{ABC})$ curves to evaluate the status of the fish community, time-lag analyses to explore the temporal variation in fish community composition in terms of relative biomass, and size spectra to examine the functional changes in the NECS fish community over the period from 2000 to 2007 .

\section{MATERIALS AND METHODS}

Study area. Fig. 1 shows the study area. It is located in the NECS, which is a large continental shelf sea, extending from $29^{\circ} 30^{\prime}$ to $31^{\circ} 30^{\prime} \mathrm{N}$ and from $123^{\circ} 00^{\prime}$ to $125^{\circ} 00^{\prime} \mathrm{E}$. The area is characterized by high productivity, due to the comprehensive influence of Yangtze River Diluted Water, Chinese Coastal Water, and the Taiwan Warm Current (Lie \& Cho 2002). The Zhoushan and Yangtze River estuary fishing grounds are both located in the area, which is known to be the spawning and feeding grounds for many commercially important species, such as hairtail Trichiurus haumela and small yellow croaker Pseudosciaena polyactis (Zhuang et al. 2006). Hence, the analysis of changes in the fish community in this area is advantageous to the evaluation of effects of the summer moratorium system on fishery resources and the marine ecosystem.

Data sources. The present paper presents an analysis of changes in the community structure in the NECS using data from bottom trawl surveys that were conducted in late April in the years 2000 to 2007. During each cruise, 19 to 22 tows of $1 \mathrm{~h}$ each ( 3 knots) were carried out with pair-trawlers fitted with $25 \mathrm{~mm}$ mesh cod end line. The sampling stations were randomly selected, generally from single sampling stations established at intervals of $0.5^{\circ} \mathrm{N} \times 0.5^{\circ} \mathrm{E}$. The abundance and biomass of all species in the catch were determined, either through total counts, if the haul was manageable, or through sub-sampling, if the catch was large.

Since April was one of the months farthest from the end of the moratorium, it was useful in evaluating the survey data regarding the more enduring effects of the moratorium, while the present study was not particularly sensitive to the immediate benefits of the closure.

Species diversity and dominant species analysis. Since the individual sizes of fish species differed greatly, the indices over the period from 2000 to 2007 in the study area were expressed in the terms of relative biomass $\left(\mathrm{kg} \mathrm{h}^{-1}\right)$ rather than number of individuals (Wilhm 1968, Xu \& Jin 2005). The Shannon-Wiener diversity index $H^{\prime}$ was used for species diversity, and 


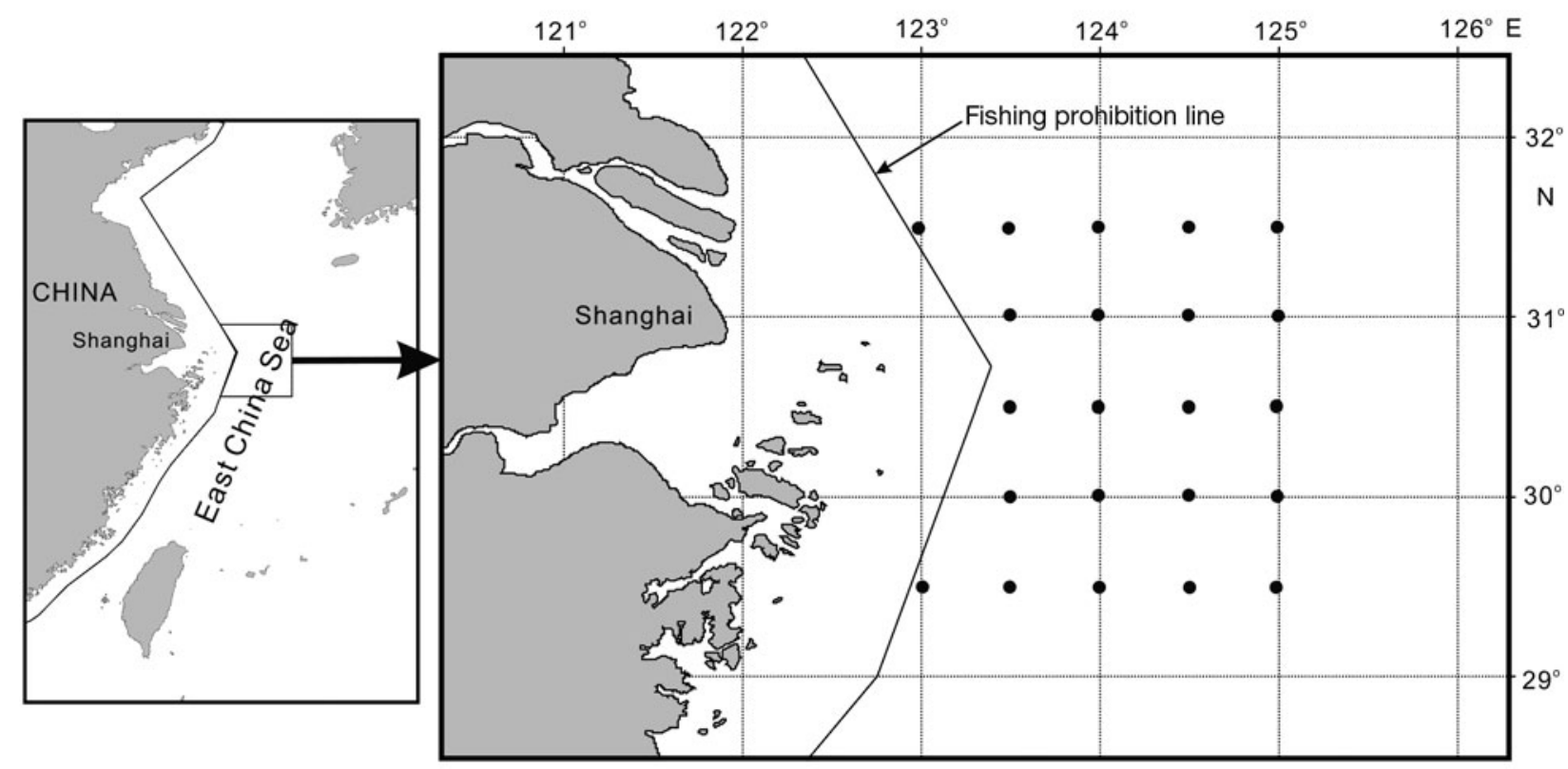

Fig. 1. Map showing the study area and sampling stations. Powered boat fishing is banned all year long inshore of the fishing prohibition line. Black points: sampling locations

Pielou's evenness index $J^{\prime}$ was used for evenness. The diversity indices N1 and N2 of Hill (1973) were also assessed, as they are less sensitive to the dominant species and the sampling effort, respectively, than those previously mentioned (Lande 1996, Blanchard et al. 2004). Any changes in these diversity indices were determined using the non-parametric Spearman rank correlation coefficient (Zar 1999).

According to Jin \& Tang (1996), Hill's N2 was also used to examine the variation in the number of dominant species. Dominant species were determined by their percentages in the total catch by weight.

Abundance-biomass comparison. An $\mathrm{ABC}$ curve consists of $2 \mathrm{~K}$-dominance curves, 1 each for biomass and abundance. The difference between the 2 curves may assume 3 possible forms, representing undisturbed, moderately disturbed and heavily disturbed fish communities (Warwick 1986, Warwick et al. 1987). For undisturbed communities, it is expected that the biomass curve lie above the abundance curve throughout its entire length when biomass is dominated by one or several large species represented by only a few individuals. At moderate disturbance, the large competitively dominant species are eliminated, and the inequality in size between the numerically dominant species and the species with high biomass is reduced, so that biomass and abundance curves are close and may intersect. As disturbance increases, communities become dominated numerically by one or several small species. In this case, the abundance curve is above the biomass curve throughout its length. We were also able to use the $W$-statistic as an indicator of the status of fish communities; this statistic is based on the relative positions of the $2 \mathrm{~K}$-dominance curves. The lower the $W$-statistic was, the more heavily the fish communities were disturbed (Blanchard et al. 2004).

$\mathrm{ABC}$ curves were constructed and the $W$-statistic was calculated using PRIMER soft (Warwick \& Clarke 1994). Time series of the $W$-statistic were assessed for significant trends using the non-parametric Spearman rank correlation coefficient (Zar 1999, Yemane et al. 2005).

Size spectrum. The size spectrum, relationships between abundance and body size regardless of taxonomy, can be calculated from simple size-abundance data. This measure was proposed by Sheldon et al. (1972) and was considered to be an index reflecting the functional properties of fish communities (Blanchard et al. 2005). The underlying hypothesis, based on trophodynamic transfer efficiencies, is that, although the richness and relative abundance of species is highly variable, the biomass and numbers of individuals (polled across all species) decreases log-linearly with size. The slope and intercept of a size spectrum are properties of the size spectrum that can be compared within a single community over time. Differences in productivity should appear as differences in intercepts, whereas differences in transfer efficiencies should appear as differences in slopes (Boudreau \& Dickie 1992, Rice \& Gislalson 1996).

The original data were catch numbers standardized by length category. Individual weights were transformed to lengths using the standard equation $L=$ $100 \times W^{1 / 3}$ (Xu \& Jin 2005, Cheng et al. 2006). All indi- 
viduals were divided into 7 size classes. Size spectra were constructed by plotting the natural logarithm of the summed numbers against the natural logarithm of midsize in the corresponding size class. Positive or negative trends in the slopes and intercepts of size spectra were evaluated by comparing the rank correlation statistics for the time series.

Temporal variation of species composition. Many community metrics are necessary in order to quantify temporal variation in the relative abundance of species in a community (Frost et al. 1995, Micheli et al. 1999). To detect changes in species composition with time, we calculated Euclidean distances of timelagged abundance matrices, regressed this distance against the square root of the time lag (linear regression), and used the slope of this relationship as an indicator for change (Collins et al. 2000, Trenkel \& Rochet 2003).

The analytical steps were as follows: the first step in the analysis was to calculate a triangular dissimilarity matrix from the species-by-time rectangular data matrix using Euclidean distances. To reduce the weighting of abundant species, we calculated Euclidean distances based on the relative biomass data through root-root transformation (Field et al. 1982, Clarke 1993); next, the Euclidean distance values were plotted against time lag for all lags below the diagonal in the triangular resemblance matrix. In the present study, there were 7 one-year time lags (2000 vs. 2001, 2001 vs. $2002, \ldots 2006$ vs. 2007), 6 two-year time lags (2000 vs. 2002,2001 vs. 2003，... 2005 vs. 2007) through 1 seven-year time lag, for a total of 28 time lags over the entire data set. The time-lag analytical approach can produce a number of general theoretical patterns with time-series data. If the regression line is significant, positive, and linear, then it implies that the assemblage in question is undergo- ing directional change. If the regression line is not significant or the slope is not significantly different from zero, then it implies fluctuation or stochastic variation over time. If the slope of the line is negative, then it implies the species composition is converging on a community-type characteristic of one of the early sample periods.

\section{RESULTS}

\section{Species diversity and dominant species}

The 4 diversity indices $\left(H^{\prime}, J^{\prime}, \mathrm{N} 1, \mathrm{~N} 2\right)$ used in the NECS during the study period are shown in Table 1. The results of time series for these indices indicated that there were no significant time trends for the 4 diversity indices ( $p>0.05$ in all cases).

Dominant species determined by using Hill's N2 and their percentages in the total catch by weight are shown in Table 2. The number of dominant species appeared to fluctuate during the study periods, with a

Table 1. Species diversity of the fish community in the northern East China Sea from 2000 to 2007. $J^{\prime}$ : Pielou's evenness; $H^{\prime}$ : Shannon-Wiener diversity index; N1: Hill's N1; N2: Hill's N2

\begin{tabular}{|ccccc|}
\hline Year & $J^{\prime}$ & $H^{\prime}$ & $\mathrm{N} 1$ & $\mathrm{~N} 2$ \\
\hline 2000 & 0.54 & 2.10 & 8.20 & 5.21 \\
2001 & 0.54 & 2.05 & 7.80 & 5.20 \\
2002 & 0.38 & 1.50 & 4.48 & 2.20 \\
2003 & 0.53 & 2.04 & 7.73 & 4.32 \\
2004 & 0.55 & 2.08 & 7.97 & 5.34 \\
2005 & 0.62 & 2.39 & 10.95 & 7.70 \\
2006 & 0.42 & 1.61 & 5.02 & 2.50 \\
2007 & 0.48 & 1.98 & 7.22 & 4.36 \\
\hline
\end{tabular}

Table 2. Dominant fish species determined by Hill's N2 and their percentages in the total catch by weight in the northern East China Sea from 2000 to 2007. K: growth coefficient; AFM: age at first maturity; information on life-history parameters is from Lin et al. (2006). *: no data; -: species was not dominant in corresponding year

\begin{tabular}{|c|c|c|c|c|c|c|c|c|c|c|c|}
\hline \multirow[t]{3}{*}{ Species } & \multirow[t]{3}{*}{ Common name } & \multirow{2}{*}{\multicolumn{2}{|c|}{$\begin{array}{l}\text { Life-history } \\
\text { parameters }\end{array}$}} & \multirow{3}{*}{2000} & \multirow{3}{*}{ - Pe } & \multirow{3}{*}{$\begin{array}{l}\text { centag } \\
2002\end{array}$} & \multirow{3}{*}{$\begin{array}{l}\mathrm{S} \text { in tota } \\
2003\end{array}$} & \multirow{3}{*}{$\begin{array}{l}\text { l catch } \\
2004\end{array}$} & \multirow{3}{*}{$\begin{array}{l}\text { by we } \\
2005\end{array}$} & \multirow{3}{*}{$\begin{array}{l}\text { ght } \\
2006\end{array}$} & \multirow{3}{*}{2007} \\
\hline & & & & & & & & & & & \\
\hline & & $K$ & AFM & & & & & & & & \\
\hline Trichiurus haumela & Hairtail & 0.46 & $1 \mathrm{yr}$ & 18.18 & 25.8 & 66.46 & 13.06 & 48.55 & 12.96 & 11.03 & 11.67 \\
\hline Setipinna taty & Scaly hairfin anchovy & 0.38 & $1 \mathrm{yr}$ & 12.49 & 4.67 & 9.23 & 43.43 & 8.26 & 7.47 & & - \\
\hline Pseudosciaena polyactis & Small yellow croaker & 0.49 & $1 \mathrm{yr}$ & 12.54 & 13.45 & - & 13.79 & 18.19 & 24.73 & 62.24 & 40.79 \\
\hline Pampus argenteus & Silver pomfret & 0.32 & $1 \mathrm{yr}$ & 19.68 & 30.54 & - & 7.18 & - & 7.35 & - & - \\
\hline Apogon lineatus & Cardinalfish & $*$ & $T^{*}$ & 17.6 & - & - & - & - & - & - & - \\
\hline Harpadon nehereus & Bombay duck & ${ }^{*}$ & * & - & 9.26 & - & - & - & - & - & 8.7 \\
\hline Engraulis japonicus & Japanese anchovy & * & * & - & - & - & - & - & 6.33 & - & 19.98 \\
\hline Erisphex potti & Spotted velvetfish & * & * & - & - & - & - & - & 9.11 & - & - \\
\hline Lophius litulon & Anglerfish & * & * & - & - & - & - & - & 17.23 & - & - \\
\hline Total & & & & 80.5 & 83.72 & 75.69 & 77.46 & 75 & 85.18 & 73.27 & 81.14 \\
\hline
\end{tabular}


maximum of 7 in 2005 and a minimum of 2 in 2002 and 2006. Small yellow croaker Pseudosciaena polyactis and hairtail Trichiurus haumela were the 2 most dominant species in the NECS, but the percentages of the 2 species were not stable over the study period.

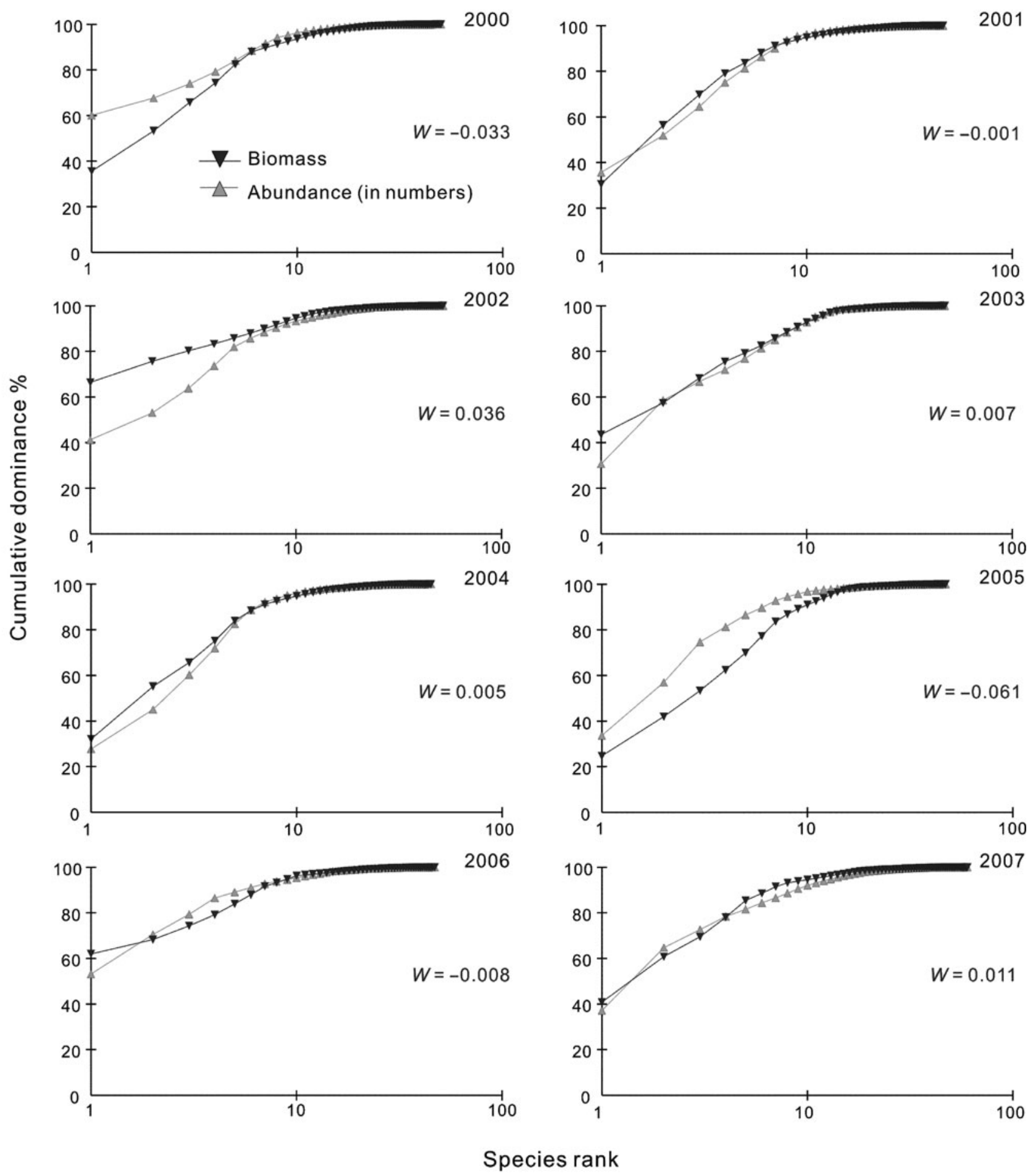

Fig. 2. Abundance-biomass comparison curves for the survey data from 2000 to 2007
Fig. 2 shows the ABC curves for the survey data in the NECS. Except for 2003, the biomass curves lie above the abundance curves, or the 2 curves cross

\section{Abundance-biomass comparison}

cross 
once or twice, which indicates moderately or heavily disturbed patterns in the fish community for the period from 2000 to 2007. Time-series analysis shows that the $W$-statistic has changed little in the last decade (Spearman $R=-0.020, p>0.05)$.

\section{Size spectrum}

The linear model with ln-transformed size class as the term fit the ln-transformed abundance well for all years. All slopes and intercepts were significantly different from 0, with all slopes being negative (Table 3). In the study periods, the trends over time in the slope and intercept were not significant $(p>0.05$ in all cases).

\section{Species composition}

Table 4 is the Euclidean distance (ED) resemblance matrix. Cells in the ED matrix represent distances between samples over time. The estimated slope of the Euclidean distances regressed against the square root of the time lag was $1.297(F=8.145$, df $=26, p=0.008$, linear $\mathrm{R}^{2}=0.238$; Fig. 3). Unfortunately, the regression

Table 3. Statistics for the fit of linear models to annual size spectra from survey data. For statistics of model fit, $\mathrm{df}=1,6$ for all regressions. Model fit, plus parameter estimates (Est.), standard errors (SE), and $t$-values for $H_{0}$ (that parameter $=$ 0 ) are based on the same number of observations ( 7 size classes) ${ }^{* * *} p<0.001$

\begin{tabular}{|c|c|c|c|c|c|c|c|c|c|}
\hline \multirow{2}{*}{ Year } & \multicolumn{3}{|c|}{ Model fit } & \multirow[b]{2}{*}{ Est. } & \multirow{2}{*}{$\begin{array}{c}\text { Slope } \\
\text { SE }\end{array}$} & \multirow[b]{2}{*}{$t$} & \multirow{2}{*}{$\overline{\text { Est. }}$} & ntercep & \multirow[b]{2}{*}{$t$} \\
\hline & $F$ & $\mathrm{p}$ & $\mathrm{R}^{2}$ & & & & & $\mathrm{SE}$ & \\
\hline 2000 & 33.17 & 0.002 & 0.87 & -6.43 & 1.12 & 7.67 & 23.60 & 3.08 & 5.76 \\
\hline 2001 & 8.18 & 0.045 & 0.67 & -5.12 & 1.79 & 2.86 & 20.00 & 4.99 & 4.01 \\
\hline 2002 & 7.92 & 0.037 & 0.61 & -3.19 & 1.13 & 2.81 & 15.28 & 3.05 & 5.01 \\
\hline 2003 & 130.43 & ${ }^{* * *}$ & 0.96 & -5.96 & 0.52 & 11.42 & 23.28 & 1.47 & 15.80 \\
\hline 2004 & 99.27 & $* * *$ & 0.96 & -7.21 & 0.72 & 9.96 & 26.77 & 2.11 & 12.66 \\
\hline 2005 & 25.21 & 0.007 & 0.86 & -4.00 & 0.80 & 5.02 & 16.83 & 2.07 & 8.13 \\
\hline 2006 & 15.98 & 0.010 & 0.76 & -4.37 & 1.09 & 4.00 & 18.60 & 3.08 & 6.04 \\
\hline 2007 & 7.20 & 0.004 & 0.59 & -5.16 & 1.93 & 2.68 & 20.38 & 5.43 & 3.75 \\
\hline
\end{tabular}

Table 4. Euclidean distance matrix over time for the fish community in the northern East China Sea

\begin{tabular}{|rrrrrrrr|}
\hline Year & 2000 & 2001 & 2002 & 2003 & 2004 & 2005 & 2006 \\
\hline 2001 & 7.84 & & & & & & \\
2002 & 9.57 & 7.63 & & & & & \\
2003 & 9.04 & 9.02 & 9.51 & & & & \\
2004 & 8.86 & 5.62 & 6.82 & 7.85 & & & \\
2005 & 9.53 & 9.76 & 10.74 & 6.8 & 7.67 & & \\
2006 & 10.19 & 9.33 & 10.46 & 7.34 & 7.32 & 6.79 & \\
2007 & 9.47 & 8.1 & 10.2 & 9.02 & 7.06 & 7.49 & 6.95 \\
\hline
\end{tabular}

coefficient $\mathrm{R}^{2}$ was small due to the high stochastic variation between sample intervals, but we could still conclude that the fish community in the present study was undergoing directional change (Collins et al. 2000).

Time series of the catch per unit effort (CPUE) of some important fish species and their percentages in the total catch were assessed using the non-parametric Spearman rank correlation coefficient to identify the species responsible for directional changes in the fish community. A total of 89 fish species were encountered in the surveys. 'Important species' occurred in all 8 survey years. The number of these species was 22, and they accounted for at least $79 \%$ of the total catch by mass during the survey period from 2000 to 2007. Therefore, these species basically represented the species composition of the study community. Time-series analysis for the CPUE of 22 populations indicated that there were significant changes in 4 populations during the study period; 2 populations increased significantly (small yellow croaker, anglerfish Lophius litulon), while 2 populations significantly decreased (silver pomfret Pampus argenteus, glowbelly). At the same time, the percentages in the total catch for these 4 populations also underwent significant changes, with 2 populations (small yellow croaker, anglerfish) increasing and 2 populations (silver pomfret, glowbelly) decreasing (Table 5). 
Table 5. Spearman rank correlation coefficients of catch per unit effort (CPUE) for 22 species and their biomass percentages in the total catch from 2000 to 2007, in the northern East China Sea. ${ }^{*} \mathrm{p}<0.05 ;{ }^{* *} \mathrm{p}<0.01$

\begin{tabular}{|llcc|}
\hline Species & Common name & $\begin{array}{c}\text { Spearman rank correlation coefficient } \\
\text { CPUE }\left(\mathrm{kg} \mathrm{h}^{-1}\right)\end{array}$ & $\begin{array}{c}\text { Biomass } \\
\text { percentage }\end{array}$ \\
\hline Argyrosomus argentatus & White croaker & & 0.405 \\
Saurida elongata & Slender lizardfish & 0.167 & 0.405 \\
Thrissa kammalensis & Rednose anchovy & -0.623 & -0.095 \\
Psenopsis anomala & Japanese butterfish & 0.619 & 0.619 \\
Trichiurus haumela & Hairtail & -0.238 & -0.643 \\
Champsodon snyderi & Benttooth & -0.238 & -0.143 \\
Acropoma japonicum & Glowbelly & $-0.905^{*}$ & $-0.857^{* *}$ \\
Minous monodactylus & Grey goblinfish & 0.635 & 0.611 \\
Lophius litulon & Anglerfish & $0.881^{* *}$ & $0.876^{* *}$ \\
Setipinna taty & Scaly halffin anchovy & -0.381 & -0.500 \\
Johnius grypotus & Corvina & 0.143 & 0.143 \\
Chaeturichthys hexanema & Pinkgray goby & 0.286 & 0.143 \\
Harpadon nehereus & Bombay duck & 0.452 & 0.357 \\
Chelidonichthys spinosus & Red gurnard & 0.286 & -0.048 \\
Bregmaceros macclellandi & Spotted codlets & 0.500 & 0.500 \\
Erisphex potti & Spotted velvetfish & 0.429 & 0.238 \\
Benthosema pterotum & Skinnycheek lanternfish & -0.024 & -0.095 \\
Engraulis japonicus & Japanese anchovy & 0.235 & 0.405 \\
Apogon lineatus & Cardinalfish & -0.643 & -0.595 \\
Pseudosciaena polyactis & Small yellow croaker & $0.810^{* *}$ & $0.905^{* *}$ \\
Lepidotrigla alata & Searobin & -0.214 & -0.214 \\
Pampus argenteus & Silver pomfret & $-0.857^{* *}$ & $-0.762^{* *}$ \\
\hline & & & \\
\hline
\end{tabular}

tine state found in the 1960s, for which the diversity indexes $H^{\prime}$ and $J^{\prime}$ were 2.59 and 0.68 , respectively ( $\mathrm{Li}$ et al. 2007). The above results suggest that the fishing moratorium system did not play a clearly positive role in the recovery of species diversity in the study area.

In the present study, the results of the ABC curves and their corresponding $W$-statistics for the fish communities suggested that the fish community in the NECS was moderately or heavily disturbed. Based on theory regarding the $\mathrm{ABC}$ method, the community is supposed to be dominated by $r$-selected species (fast-growing, small, opportunistic) in a disturbed state (Warwick 1986, Warwick \& Clarke 1987). During our study period, the dominance of $r$-selected species

\section{DISCUSSION AND CONCLUSIONS}

The summer fishing moratorium has been fully implemented in the ECS for $>10 \mathrm{yr}$. One might expect the moratorium to have played a positive role in improving the structure and function of the fish community and restoring ecosystem health in the study area. However, the above results provide no evidence that the fish community developed in the expected direction following the implementation of the moratorium. Most of community metrics indicated that the fish community did not change in the expected positive directions.

Diversity indices are classic in the research field of community ecology. Since there is a positive relationship between diversity and ecosystem functions and structures (Worm et al. 2006), the metrics of species diversity have been used widely to capture the changes in fish communities. In the NECS, the fish community had experienced great losses of species richness and species diversity due to over-fishing during recent decades (Cheng et al. 2006, Li et al. 2007). The recovery of species diversity was expected following the declaration of summer moratorium. Unfortunately, none of the diversity indices showed a significant directional change in the studied area during the entire study period, and the present diversity indices were clearly lower than those determined for the pris- had increased significantly in the fish community compared to their presence in the pristine state in the 1960s (Cheng et al. 2006, Li et al. 2007). On the one hand, the dominance of small, fast-growing fishes had increased significantly (Li et al. 2007). On the other hand, the biological parameters, including average body length and median age at maturity, of some typifying species of the community, such as small yellow croaker and hairtail, had decreased compared to those determined in the pristine state before the 1980s, showing the survival strategy of these stocks to have changed to that of $r$-selected species (Zhou et al. 2002, Lin \& Cheng 2004). Details on the present life-history parameters of the dominant species are shown in Table 2.

After implementation of the summer moratorium, one might have expected decreased stress in the study community. Although the summer fishing moratorium system was strictly implemented by the Chinese Government, the moratorium did not significantly decrease the stress on the fish community in the study area, as indicated by $W$-statistics (Fig. 2). This is probably due to the seriously increased fishing pressure after the 3 mo annual moratorium implementation.

Cheng et al. (2006) compared trawl survey data collected in the NECS in 1962 with that collected in 2006 and found there was a decreasing trend in the slope of the size spectrum, reflecting changes in turnover rate toward a relative decline. In our study, no significant 
trends in the slopes or intercepts of size spectra were found in the study periods, which indicated that productivity and turnover rate of the community studied did not exhibit recovery. We might conclude that the effects of the summer moratorium on community function in the NECS were not obvious.

Although no time trends were found in the aggregate indicators of the study community, including species diversity, $W$-statistics, and the slope and intercept of the size spectrum, a directional change in the composition of the fish community in terms of relative biomass was detected following the implementation of the summer fishing moratorium system. The most obvious characteristics of the change were that the temporal trends in the dominance of the main target species were variable. After the summer fishing moratorium was carried out, temporal changes in the relative and absolute biomass of dominant species were different. Above all there were 3 forms of change, namely increase, fluctuation, and decrease. Temporal changes of the 3 most dominant species, small yellow croaker Pseudosciaena polyactis, hairtail Trichiurus haumela, and silver pomfret Pampus argenteus followed the 3 forms, respectively.

The CPUE of small yellow croaker, which was considered one of the most dominant species in the study area, increased significantly from 2000 to 2007 (Table 5). According to previous studies (Lin \& Cheng 2004), there were 2 main reasons contributing to the increase in the population of small yellow croaker. First, was the early maturity of the species, which benefitted the recruitment, and, secondly, the nursery period coincided with the summer moratorium. The annual spawning season for small yellow croaker is from April to June, and the following months, July to September, represent a critical stage in juvenile development. Therefore, the summer moratorium, which runs from 16 June to 15 September, increased the survival rate of juveniles and thereby promoted the stock.

The population of hairtail was fluctuating during the study period, which could be attributed to the unstable population structure (Mi 1997, Zhou et al. 2002). The hairtail population was predominantly in the lower age groups, and the annual recruitment clearly affected the total biomass of the population. The fluctuation of the hairtail population may be caused by the changes in environmental conditions that affect the recruitment period.

Silver pomfret was one of the most commercially valuable species in the ECS, and had been confronted with more intense fishing pressure than other species for a long time. Moreover, it was the main target species for gill net fishing, which was not banned by the moratorium. Therefore, silver pomfret was under intense fishing pressure, even during the moratorium.
Consequently, it did not recover in spite of the implementation of the moratorium (Table 5).

In summary, the results of the present study revealed that the fish community structure of the NECS was not stable, but underwent directional changes in terms of relative biomass composition following the implementation of the summer fishing moratorium. Since the dominance of small yellow croaker increased significantly, the dominance of other stocks would be expected to decline correspondingly. The fish community structure might, therefore, become less diverse. The changes in species composition somehow did not result in positive changes in the functioning of fish community. The results of $\mathrm{ABC}$ analysis showed that the fish community was still moderately disturbed. And the indicators related to the stability and functioning of fish community, such as biodiversity and the slope and intercept of the size spectrum, showed no positive trends during the study periods.

All of these factors indicated that the summer moratorium was only beneficial to certain stocks, but did not play a positive role in the restoration process of fish community structure and function in the study area. The moratorium merely shifted fishing efforts from the summer to other seasons, and annual fishing effort was not effectively reduced. Under the heavy fishing pressure, the structure and function of the fish community could not quite recover. To ensure the maintenance of a healthy ecosystem, a comprehensive set of restrictions on fishing efforts must be imposed on the fishery in the area. According to successful programs attempted around the world, creating MPAs (marine protected areas) or no-take zones around important spawning and nursery sites may help depleted local fisheries recover, as well as helping to reduce the impact of fisheries on marine ecosystems.

Acknowledgements. We thank R. R. Edpalina for helpful comments on the manuscript. Thanks also to all scientific staff and crew members for their assistance in collecting data during the surveys. The original data collection was funded by the Ministry of Science and Technology of China.

\section{LITERATURE CITED}

Blanchard F, Leloc'h F, Hily C, Boucher J (2004) Fishing effects on diversity, size and community structure of the benthic invertebrate and fish megafauna on the Bay of Biscay coast of France. Mar Ecol Prog Ser 280:249-260

Blanchard JL, Dulvy NK, Jennings S, Ellis JR, Pinnegar JK, Tidd A, Kell LT (2005) Do climate and fishing influence size-based indicators of Celtic Sea fish community structure? ICES J Mar Sci 62:405-411

Boudreau PR, Dickie LE (1992) Biomass spectra of aquatic ecosystems in relation to fisheries yield. Can J Fish Aquat Sci 49:1528-1538

Cheng Y, Fan W (2001) Study of time-serial analysis of marine capture yield in East China Sea region. J Fish Sci China 6:81-85 (in Chinese, with English abstract) 
Cheng J, Yu L (2004) The change of structure and diversity of demersal fish communities in the Yellow Sea and East China Sea in winter. J Fish China 28:29-34 (in Chinese, with English abstract)

Cheng J, Yan L, Lin L, Yu L and others (1999) Analyses on the fishery ecological effect of summer close season in the East China Sea region. J Fish Sci China 6:1-85 (in Chinese, with English abstract)

Cheng J, Ding F, Li S, Yan L, Li J, Liang Z (2006) Changes of fish community structure in the coastal zone of the northern part of East China Sea in summer. J Nat Resour 21: 775-781 (in Chinese, with English abstract)

Clarke KR (1993) Non-parametric multivariate analyses of changes in community structure. Aust J Ecol 18:117-143

Collins SL, Micheli M, Hartt L (2000) A method to determine rates and patterns of variability in ecological communities. Oikos 91:285-293

Field JG, Clarke KR, Warwick RM (1982) A practical strategy for analysing multispecies distribution patterns. Mar Ecol Prog Ser 8:37-52

Frost TM, Carpenter SR, Ives AR, Kratz TK (1995) Species compensation and complementarity in ecosystem function. In: Jones CG, Lawton JH (eds) Linking species and ecosystems. Chapman \& Hall, London, p 224-239

Greenstreet SPR, Hall SJ (1996) Fishing and the ground-fish assemblage structure in the north-western North Sea: an analysis of long-term and spatial trends. J Anim Ecol 65: $577-598$

Hall SJ (1999) The effects of fishing on marine ecosystems and communities. Blackwell Science, Oxford

Hill MO (1973) Diversity and evenness: a unifying notation and its consequences. Ecology 54:427-432

Hollingworth C (ed)(2000) Ecosystem effects of fishing. ICES J Mar Sci 57:465-791

Jackson JBC, Kirby MX, Berger WH, Bjorndal KA and others (2001) Historical overfishing and the recent collapse of coastal ecosystems. Science 293:629-638

Jin X, Tang Q (1996) Changes in fish species diversity and dominant species composition in the Yellow Sea. Fish Res 26:337-352

Lande R (1996) Statistics and partitioning of species diversity, and similarity among multiple communities. Oikos 76 : $5-13$

Li J, Li S, Ding F, Cheng J (2007) Analysis on annual change of fish diversity in Yangtze estuary offshore water area. J Fish Sci China 14:637-643 (in Chinese, with English abstract)

Lie HJ, Cho CH (2002) Recent advances in understanding the circulation and hydrography of the East China Sea. Fish Oceanogr 11:318-328

Lin L, Cheng J (2004) An analysis of the current situation of fishery biology of small yellow croaker in the East China Sea. Period Ocean Univ China 34:565-570 (in Chinese, with English abstract)

Lin L, Cheng J, Ling J, Zhang H (2006) First capture sizes of major commercial fishes? in the East China Sea Region. J Fish Sci China 13:250-256 (in Chinese, with English abstract)

Ling J, Li S, Yan L (2006) Analysis on the utilization of main fishery resources in the East China Sea. Mar Fish 28: 111-116 (in Chinese, with English abstract)

Editorial responsibility: Kenneth Sherman, Narragansett, Rhode Island, USA
Magurran AE (1988) Ecological diversity and its measurement. Chapman \& Hall, London

Mi C (1997) A study on resources, stock structure and variation of reproductive habit of hairtail, Trichiurus haumela in the East China Sea. J Fish Sci China 4:7-14 (in Chinese, with English abstract)

> Micheli F, Cottingham KL, Bascompte J, Bjornstad ON and others (1999) The dual nature of community variability. Oikos 85:161-169

Rice JC (2000) Evaluating fishery impacts using metrics of community structure. ICES J Mar Sci 57:682-688

Rice J, Gislason H (1996) Patterns of change in the size spectra of numbers and diversity of the North Sea fish assemblage, as reflected in surveys and models. ICES J Mar Sci 53:1214-1225

> Rochet MJ, Trenkel VM (2003) Which community indicators can measure the impact of fishing? A review and proposals. Can J Fish Aquat Sci 60:86-99

Sheldon RW, Prakash A, Sutcliffe WH (1972) The size distribution of particles in the ocean. Limnol Oceanogr 17:327-340

Trenkel VM, Rochet MJ (2003) Performance of indicators derived from abundance estimates for detecting the impact of fishing on a fish community. Can J Fish Aquat Sci 60:67-85

Warwick RM (1986) A new method for detecting pollution effects on marine macrobenthic communities. Mar Biol 92:557-562

Warwick RM, Clarke KR (1994) Relearning the ABC: taxonomic changes and abundance/biomass relationships in disturbed benthic communities. Mar Biol 118:739-744

Warwick RM, Pearson TH, Ruswahyuni (1987) Detection of pollution effects on marine macrobenthos: further evaluation of the species abundance/biomass method. Mar Biol 95:193-200

Wilhm JL (1968) Use of biomass units in Shannon's formula. Ecology 49:153-156

- Worm B, Barbier EB, Beaumont N, Duffy JE and others (2006) Impacts of biodiversity loss on ocean ecosystem services. Science 314:787-790

Xu B, Jin X (2005) Variation in fish community structure during winter in the southern Yellow Sea over the period 1985-2002. Fish Res 71:79-91

Xu K, Liu Z (2007) The current stock of large yellow croaker Pseudosciaena crocea in the East China Sea with respects of its stock decline. J Dalian Fish Coll 22:392-396 (in Chinese, with English abstract)

Yan L, Ling J, Li J, Lin L, Cheng J (2006) Simulative analysis on results of summer closed fishing in the East China Sea with Ricker population dynamic pool model. J Fish Sci China 13:85-91 (in Chinese, with English abstract)

Yemane D, Field JG, Lesile RB (2005) Exploring the effects of fishing on fish assemblages using Abundance Biomass Comparison (ABC) curves. ICES J Mar Sci 62:374-379

Zar JH (1999) Biostatistical analysis, 4th edn. Prentice Hall, Engelwood Cliffs, NJ

Zhou Y, Xu H, Liu Z, Xue L (2002) A study on variation of stock structure of hairtail, Trichiurus haumela in the East China Sea. Ocean Univ (Nat Sci) 21:314-320

Zhuang P, Wang Y, Li S, Deng S, Li C, Ni Y (2006) Fishes of the Yangtze Estuary. Shanghai Scientific \& Technical Publishers, Shanghai (in Chinese)

Submitted: December 15, 2008; Accepted: April 20, 2009

Proofs received from author(s): June 26, 2009 